\title{
5 Physiological Mechanisms and the Evolution of Plasticity
}

\author{
Cristina C. Ledón-Rettig and Erik J. Ragsdale \\ Indiana University
}

\section{CONTENTS}

5.1 Introduction and Scope

5.2 How Is Physiology Involved in Phenotypic Plasticity?.................................. 114

5.3 Physiological Mechanisms Promoting the Evolution of Plastic Phenotypes... 116

5.3.1 Mechanisms Promoting Plasticity in Developmental Transitions.... 116

5.3.2 Mechanisms Promoting Plasticity in Morphology ............................ 118

5.3.3 Mechanisms Promoting Plasticity in Behavior ................................. 120

5.4 Physiological Mechanisms, Pleiotropy, and Evolution .................................. 122

5.4.1 Physiological Pleiotropy as a Constraint ......................................... 122

5.4.2 Physiological Pleiotropy as an Integrator ......................................... 124

5.4.3 Breaking Physiological Pleiotropy..................................................... 124

5.4.4 Variability in Physiological Pleiotropy as Substrate for Evolution... 125

5.4.5 How Does Physiological Divergence Promote Diversification? ........ 127

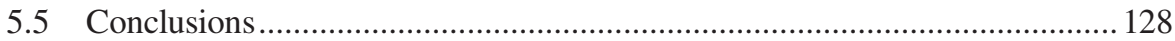

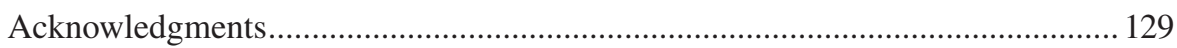

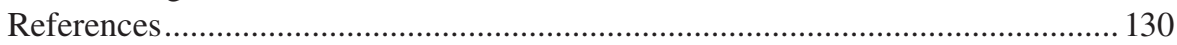

\subsection{INTRODUCTION AND SCOPE}

Phenotypic plasticity is fundamentally a physiological phenomenon. Whether the phenotypic outcome of plasticity is the preservation of form ('homeostasis'), fleeting change, more gradual but reversible change ('acclimation'), or largely irreversible change ('developmental plasticity'), physiology provides the proximate link between the environment and an individual's phenotypic development and expression. A view into the physiological mechanisms underlying plastic traits, particularly plastic traits that have undergone evolutionary divergence, can inform how these traits evolve and the constraints that prevent them from evolving in certain ways.

We begin this chapter by introducing why and how physiology is intimately connected to phenotypic plasticity. We then present examples of how the divergence of physiological mechanisms may have promoted phenotypic divergence in plasticity 
among populations and species, a phenomenon that has been studied under the names of 'genetic accommodation' and 'genetic assimilation' (see Scheiner and Levis 2021 and Levis and Pfennig 2021 in this volume). We rely heavily on examples involving organisms derived from natural populations to highlight the ubiquity of physiological evolution and its impacts on phenotypic diversity. In the interest of keeping the chapter focused, we will not be addressing physiological mechanisms in plants, which warrant a chapter entirely of their own (for reviews see Sultan 2000; Gilroy and Trewavas 2001; Herman and Sultan 2011). We then discuss how physiological mechanisms and their affected traits evolve (or fail to evolve), sometimes even promoting reproductive isolation. Finally, we argue that characterizing the physiological mechanisms underlying plastic phenotypes can offer us a more nuanced understanding of the evolutionary potential and constraints of phenotypic plasticity.

\subsection{HOW IS PHYSIOLOGY INVOLVED IN PHENOTYPIC PLASTICITY?}

Most plastic phenotypes are influenced by genetic factors (Pigliucci 2001; see also Goldstein and Ehrenreich 2021 in this volume). At the same time, the ability of organisms to be plastic can itself be modified by the environment (Beaman et al. 2016). Thus, one can argue that most cases of phenotypic plasticity have a genetic and environmental basis. Regardless, there must be some connection between these causal factors and the phenotypes on which natural selection acts. Physiology is likely, in most cases, to be the black box linking these proximal factors to their resulting phenotypes. Further, physiological mechanisms themselves have genetic underpinnings, can harbor genetic variation, and can therefore evolve, producing divergence in plastic phenotypes.

Physiological changes are often at the core of phenotypic responses to environmental variation because physiology is sensitive to environmental change and often systemic. Such changes can thus coordinate responses among traits so that they work together. In particular, endocrine systems are environmentally responsive and can influence several traits simultaneously, sometimes in contrasting ways, through differences in hormone transport, metabolism, and the sensitivity of tissues to hormones. Importantly, many hormone receptors are ligand-gated transcription factors with DNA-binding abilities, such that intercellular signals directly influence gene expression and the corresponding responses in phenotypes (Aranda and Pascual 2001). Further, the modularity of endocrine systems provides multiple ways in which they can evolve to provide evolutionary divergence in plastic traits. Finally, hormones function not only as homeostatic regulators but as signals during development, giving them a special role in developmental plasticity (Nijhout and Wheeler 1982; Dufty et al. 2002). For these reasons, we primarily focus on hormonal mechanisms of plasticity, although they are but one of several physiological systems to consider.

With respect to developmental plasticity, physiological mechanisms can link environmental signals to both continuous and discrete plasticity outcomes. For instance, the butterfly Bicyclus anynana is known to display large, bright ventral hindwing eyespots during the wet season, whereas the same eyespots are small and drab during 
the dry season. Although these alternate forms are more common than intermediate forms in nature since different broods coincide with different seasons, it is clear that wing patterns change continuously with temperature (Brakefield and Reitsma 1991; Holloway and Brakefield 1995). Differences in temperature, in turn, affect the amounts of ecdysteroid hormones present at a critical larval period during which eyespot formation is determined (Koch et al. 1996; Brakefield et al. 1998). Here, a continuous level of an environmentally sensitive physiological mediator results in continuous phenotypic variation, often referred to as a reaction norm (Figure 5.1).

Alternatively, physiological mediators can evolve such that their relationship with a phenotypic output occurs as a threshold between multiple alternatives, or 'polyphenism' (Figure 5.1). Other species of butterflies that are closely related to B. anynana, for example, share ecdysteroid signaling as a physiological mechanism underlying ventral hindwing eyespot formation, yet individuals respond to
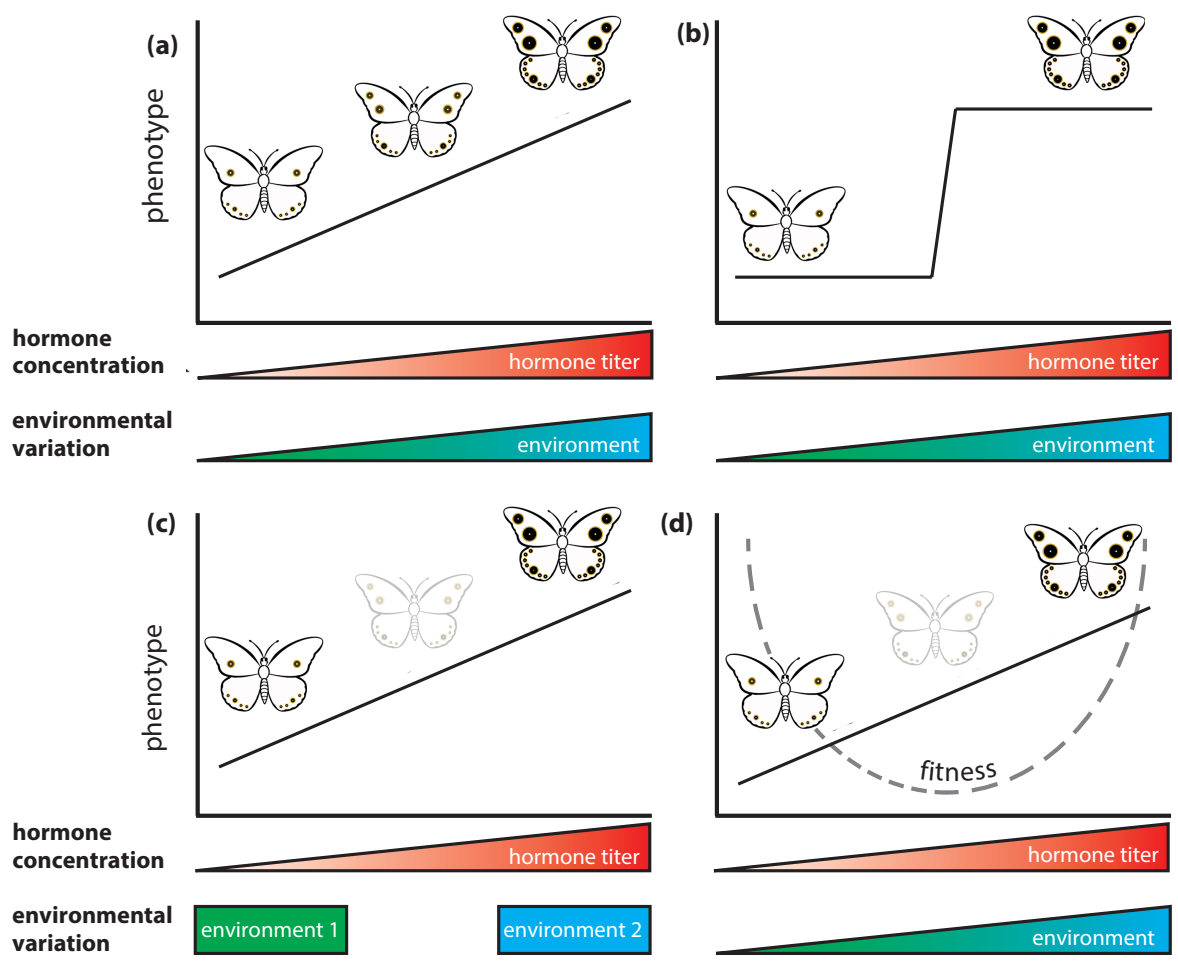

(d)

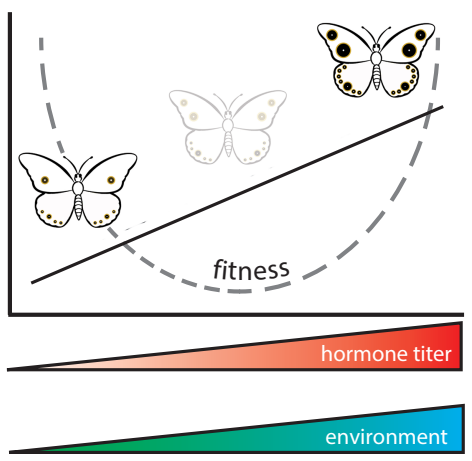

FIGURE 5.1 Continuous and threshold traits and how they relate to physiological mediators. Continuous plasticity, often referred to as a 'reaction norm,' can be generated by a continuous level of an environmentally sensitive hormone (a). Alternatively, the relationship between phenotypic outcomes and as environmentally sensitive hormone can occur in a threshold fashion, often referred to as 'polyphenism' (b). Sometimes polyphenisms are only apparent because organisms encounter discrete environmental variation, as in seasonal polyphenisms (c), or because the fitness of intermediate phenotypes is very low and they are quickly removed from populations (d). 
temperature in a threshold pattern where intermediate eyespots are rare even when they are exposed to intermediate temperatures as larvae (van Bergen et al. 2017). Likewise, males of the bull-headed dung beetle Onthophagus taurus are either hornless or display fantastic horns if below or above a critical body size, respectively, even though the physiological mechanism informing this decision is a continuous titer of JH (Emlen and Nijhout 1999). Thus, polyphenism does not just require physiological mechanisms in order to convert externally triggered signals into phenotypic outcomes, as does continuous plasticity: it also requires physiological mechanisms that canalize the expression of alternative phenotypes (Sieriebriennikov et al. 2017).

In the following section, we highlight different systems that have been used to understand how the evolution of physiological - often, hormonal - mechanisms have led to divergence in plastic traits. One approach used to understand how this occurs is to compare the physiological plasticity of lineages (populations or species) with a derived trait with closely related lineages lacking that trait, i.e., having the ancestral state. If manipulations of the underlying mechanism in an ancestral-type lineage produce the derived trait, or vice versa, this provides evidence that the physiological mechanism was a crucial mediator of that trait's evolutionary change.

\subsection{PHYSIOLOGICAL MECHANISMS PROMOTING THE EVOLUTION OF PLASTIC PHENOTYPES}

\subsubsection{Mechanisms Promoting Plasticity in Developmental Transitions}

The evolution of developmental transitions is a widespread mechanism of phenotypic change in groups ranging from plants to primates (Gould 1977; Raff and Wray 1989). One of the most compelling examples of where tweaks to developmental timing have potentially led to diversification is in salamanders. Ancestrally, the salamander life-cycle begins with an aquatic egg that hatches into a gilled, aquatic larva, which then undergoes metamorphosis to become an air-breathing and terrestrial adult (Duellman and Trueb 1986). From this state, several lineages have independently evolved to become paedomorphic, whereby larvae do not undergo metamorphosis but become sexually mature while retaining their larval form (Alberch et al. 1979; Wiens et al. 2005). It has long been assumed that evolutionary shifts in thyroid hormone (TH) signaling - the key pathway mediating metamorphic transitions in amphibians (Denver 1997; Buchholz et al. 2003) - preceded the emergence of these unique life cycles. Matsuda (1982) noted that some salamander species display facultative paedomorphism in response to their environmental conditions, and he suggested that genetic assimilation of once environmentally sensitive TH signaling was responsible for the evolution of obligatory paedomorphic forms.

At a mechanistic level, these environmentally mediated physiological changes are best understood in the almost entirely paedomorphic axolotl (Ambystoma mexicanum). In this species, a pituitary deficiency in TH secretion is controlled by just a few loci, as confirmed by quantitative trait loci (QTL) analysis, and the penetrance of these loci depends on genetic background (Voss et al. 2012; Johnson and Voss 2013). Although the endocrine mechanisms are unknown in the facultative paedomorph $A$. talpoideum, the expression of paedomorphs can be increased using artificial selection 
over just four generations (Semlitsch and Wilbur 1989). It seems plausible that, given the presence of heritable genetic variation in a physiological mediator of $\mathrm{TH}$ signaling, a population of organisms that were once facultatively paedomorphic like A. talpoideum could evolve to be constitutively paedomorphic like A. mexicanum. Indeed, stressful environmental conditions will occasionally cause A. mexicanum individuals to metamorphose (Smith 1969), possibly a vestige of the phenotype's once environmental control.

The ability to change developmental course when confronted by or anticipating inhospitable environments is featured across all reaches of multicellular life. In vertebrates, this ability is often regulated by the stress axis (Crespi and Denver 2005; Wada 2008). Specifically, in salamanders and frogs, environment-dependent upregulation of the glucocorticoid corticosterone (hereafter, CORT) interacts intimately with TH signaling to accelerate development (Denver 1997; Johnson and Voss 2013; Bohenek 2019). As an example, divergence in CORT production, secretion, transport, or reception may have led to divergence in the relative timing of metamorphosis in a group of frogs called spadefoot toads (families Pelobatidae and Scaphiopodidae). Spadefoot species vary widely in how sensitive their developmental pace is to environmental conditions. At one extreme, Couch's spadefoot toad (Scaphiopus couchii) lays eggs ephemeral ponds and is canalized for a very brief larval period. In contrast, the Western spadefoot toad (Pelobates cultripes) breeds in long-lasting ponds and has substantial plasticity in developmental timing, while the Mexican spadefoot toad (Spea multiplicata) breeds in ponds of intermediate duration and has intermediate plasticity. Commensurate with their variable levels of developmental plasticity, $P$. cultripes and Sp. multiplicata respond to pond drying with higher levels of CORT and $\mathrm{TH}$ - which work synergistically to accelerate metamorphosis - but the same hormones in Sc. couchii do not respond to this environmental stressor (Kulkarni et al. 2017). Thus, the atypically brief and unresponsive developmental speed of Sc. couchii may be the consequence of evolutionary divergences in the stress and thyroid axes.

Another example of a plastic developmental transition associated with diversification of life-histories is in nematodes. In several groups of mostly terrestrial species, adverse environments trigger early larvae to enter developmental arrest as an alternative third stage, the dauer larva. The dauer is a metabolically quiescent stage that awaits the return of a favorable environment, often through dispersal to a new one, upon which the animal resumes development. In the model nematode Caenorhabditis elegans, the decision to enter dauer is made through physiological cascades that begin with the sensation of external small molecules (ascaroside pheromones) and internal metabolites, followed by signaling through conserved endocrine pathways such as insulin/insulin-like growth factor (IGF), transforming growth factor (TGF)- $\beta$, and the steroid hormone DAF-12-dafachronic acid (Hu 2007). In principle, changes to either the induction cues or downstream switches might be selected in response to local pressures. Indeed, genetic variation in this plastic response has been found among populations of a single species (Viney et al. 2003; Green et al. 2013), as have larger differences between deep evolutionary lineages (Ogawa et al. 2011; Bose et al. 2012; Falcke et al. 2018). How these differences correlate with adaptive evolutionary changes is still unknown, though it seems likely that the dauer stage has played a key role in the diversification of nematode life-histories. This is 
because of the dauer's association with the invertebrate vectors often needed for dispersal (e.g., Herrmann et al. 2006; Kiontke and Sudhaus 2006): any physiological change that enables a switch to a new dispersal host may provide the initial step in the colonization of previously inaccessible habitats.

Perhaps the most striking example in which the dauer stage may have facilitated the evolution of divergent life-histories is the infective juvenile (IJ/iL) stage of nematode parasites. Several groups of parasites, each with an alternative third stage used to infect their insect or vertebrate hosts, have independently evolved from free-living lineages (Blaxter et al. 1998). Given the long-recognized physiological similarities of IJs to dauers (Rogers and Sommerville 1963), it has been proposed that dauers are a preadaptation for parasitism ('dauer hypothesis'; Hotez et al. 1993). Molecular details of parasites' entry into the IJ stages have provided increasing support for this scenario. For example, in the intestinal parasites Strongyloides stercoralis and S. papillosus (Strongyloididae), as well as the hookworm Ancylostoma caninum (Strongylidae), a dauer inhibitor in C. elegans, the hormone $\Delta 7$-dafachronic acid, blocks the transition to the IJ stage (Ogawa et al. 2009; Wang et al. 2009). Similarly, more recent RNAi-knockdown experiments in Strongyloides ratti confirmed that the decision is made through the hormone's likely target, the Vitamin D receptor homolog DAF-12 (Dulovic and Streit 2019). Genetic perturbations have also shown that the homolog of FoxO in S. stercorails controls IJ entry, also similar to the dauer stage of C. elegans and Pristionchus pacificus (Castelletto et al. 2009). Increasing evidence thus shows it is likely that repurposing the physiological response in a plastic decision has facilitated a radiation of lifestyles in nematodes, including the evolution of parasitism, independently in distantly related clades.

A final example of developmental transitions potentially linked to ecological diversity is another type of dispersal dimorphism: insect wing polyphenisms. Feeding and dispersal polyphenisms are both widespread in insects and perhaps one of the major reasons for their evolutionary success (Simpson et al. 2011). For example, in aphids, females can develop into wingless or winged morphs in response to local cues, and several molecular details of this response's physiology have been characterized, including roles for JH signaling (Hardie 1980), ecdysone signaling (Vellichirammal et al. 2017), and the modification of insulin signaling by micro-RNAs (Shang et al. 2020). It is interesting to note that these signaling pathways, which have ancient roles in molting and growth, have been co-opted to instruct developmental plasticity in other traits such as dauer formation in nematodes (this section), horn development in dung beetles (Section 5.3.2), and eusociality in all insects that possess it (Section 5.3.3). Thus, an issue to resolve with future research is how, at a macroevolutionary scale, physiological systems diverge to produce entirely new developmental functions.

\subsubsection{Mechanisms Promoting Plasticity in Morphology}

Evolution has offered us an astounding bounty of morphological variation that can be easily measured, not only in living animals but also through fossils, so it is understandable that most adaptive radiations have been studied through the lens of morphology. Physiology can shape morphology, especially during development, so 
what is the role of physiological divergence in the evolution of plastic morphologies? One group of fish, pupfish (Cyprinodontidae) that currently inhabit the Death Valley regions of California, has recently undergone morphological divergence as a consequence of both natural and semi-natural experiments (Lema 2020), allowing researchers to answer this question.

Specifically, one species that is endemic to a single pond, the Devil's Hole pupfish (Cyprinodon diabolis), has recently evolved to be morphologically distinct from other species, having a small body size, relatively large head and eye sizes, and no pelvic fins (Wales 1930). It was historically suspected that pelvic fin development in this species was in some way responsive to temperature because some C. diabolis individuals developed pelvic fins, albeit rarely, while some individuals of C. nevadensis - a closely related pupfish species that generally does develop pelvic fins - lacked them (Wales 1930; Miller 1948). More compelling evidence arose for this hypothesis with the establishment of artificial refuges meant to mitigate the extinction risk of this species. Within four years, $C$. diabolis from populations within the refuges, which contained cooler water than Devil's Hole, were much longer than the largest conspecific $C$. diabolis in Devil's Hole and developed relatively shorter heads (Wilcox and Martin 2006).

More recent studies have aimed to determine whether ancestral temperatureand diet-induced plasticity in endocrine mechanisms led to the unique morphologies of $C$. diabolis. To do this, researchers exposed an ancestral-type lineage, C. n. amargosae, to environmental conditions experienced by the derived species, $C$. diabolis. In response to more restricted food and modestly higher water temperatures, $C$. $n$. amargosae individuals were less likely to develop pelvic fins and also developed other attributes typical of $C$. diabolis (Lema and Nevitt 2006). Importantly, larval $C$. $n$. amargosae that were food-restricted had lower wholebody levels of $\mathrm{T}_{4}$ (thyroxine, which is converted to biologically active $\mathrm{T}_{3}$ in tissues), supporting the hypothesis that the observed morphological changes were brought about by temperature- and diet-dependent TH signaling. Finally, these morphological changes, including the loss of pelvic fins, could be recapitulated by treating larval C. n. amargosae with inhibitors of TH (Lema 2014). Thus, a close relative of the Devil's Hole pupfish exhibits morphological plasticity in response to energetically challenging conditions that are at least partially mediated by changes in $\mathrm{TH}$ signaling. If variation in such hormonally mediated plasticity was also present in the ancestor of Devil's Hole pupfish, that variation may have been selected to produce the species' defining morphological attributes.

Another example of rapid physiological divergence can be found among populations of Onthophagus taurus, a beetle that exhibits a dramatic nutrition-dependent polyphenism in horn development. As mentioned above, the common insect hormone $\mathrm{JH}$ regulates horn expression in males, with low and high titers of $\mathrm{JH}$ resulting in hornless and horned individuals, respectively. Although native to Mediterranean Europe (Balthasar 1963), O. taurus has been distributed among different continents in the last 60 years by human introduction (Silva et al. 2016), allowing a comparison of JH titers and its consequences among multiple very recently diverged populations. These populations differ with respect to the degree and timing of their sensitivity to $\mathrm{JH}$ and, correspondingly, in the threshold that determines horn production (Moczek 
et al. 2002). Specifically, Western Australian individuals induce expression at only very large body sizes, and these individuals also require substantially higher JH titers later during development when compared to their counterparts in the Eastern United States (Moczek and Nijhout 2002). These differences in threshold induction have been maintained in the laboratory after several generations, suggesting that the divergence of a physiological mechanism between the two populations has been genetic.

We have seen now that morphological evolution between two lineages can happen rapidly, but if we zoom out in evolutionary time, we find that physiological mechanisms may ultimately promote a rich, phylogenetic landscape of morphological diversity. An emerging model for studying this is a family of nematodes, Diplogastridae, which - in addition to responding to environments with dauer development - exhibit polyphenism in their feeding morphologies. Nematodes with the polyphenism typically have one morph that has more or larger teeth that enable a broader diet than does its other morph, usually including the consumption of other nematodes as prey (Serobyan et al. 2014; Wilecki et al. 2015). Comparative analyses of form in these nematodes have demonstrated that developmental plasticity is associated with an evolutionary radiation of feeding forms, including those with structural novelties (Susoy et al. 2015). Consequently, mouthparts have likely taken on a wide array of feeding functions in Diplogastridae relative to non-polyphenic outgroups, as both implied by structure (Fürst von Lieven and Sudhaus 2000) and determined empirically (Susoy et al. 2016; Ledón-Rettig et al. 2018).

Was this adaptive radiation spurred by underlying physiological change? Phylogenetic and functional genetic studies have together outlined a program for testing this idea. First, multiple molecular factors making up a developmental 'switch' between two environmentally sensitive morphologies have been identified in one particular diplogastrid model, Pristionchus pacificus. Importantly for the study of trait divergence, these factors include genes whose copy number and expression vary among populations and species with different plasticity phenotypes (Ragsdale et al. 2013; Bui et al. 2018). In a study linking polyphenism regulation to morphological effects, Sieriebriennikov and colleagues (2020) discovered a nuclear receptor (NHR-1) that influences both the switch decision and plastic morphology itself. Interrogation of this and other polyphenism regulators (e.g., NHR-40; Kieninger et al. 2016) may thus identify the inter- or intracellular processes the switch controls to instruct alternative forms. Second, comparative studies have begun to determine macroevolutionary changes in both (1) the molecules controlling the switch (Ragsdale and Ivers 2016; Sieriebriennikov et al. 2018; Biddle and Ragsdale 2020) and (2) the molecular targets of the switch (Bui and Ragsdale 2019; Sieriebriennikov et al. 2020; Casasa et al. 2021). Together, these identified changes will enable us to track, in macroevolutionary time, how the physiological mediators of development have influenced morphogenesis in a group with diverse, plastic forms.

\subsubsection{Mechanisms Promoting Plasticity in Behavior}

To examine how environmentally sensitive physiological changes can result in population or species differences in behavior, we return to the pupfish system. We will recall that an ancestral-type cyprinodont species, C. n. amargosa, was used 
to demonstrate temperature- and diet-dependent plasticity in morphology (Lema and Nevitt 2006). This subspecies also alters the degree of its aggressive behaviors in response to seasonal variation in population density and water temperature. By comparison, a population of its closely related subspecies that inhabits Big Spring (C. n. mionectes), an environmentally stable springhead, is relatively aggressive all year round. A good candidate for studying aggression is arginine vasotocin (AVT), a peptide hormone produced in the preoptic area of the hypothalamus. Among its other roles, this hormone acts with the central nervous system to regulate social behavior (Goodson and Bass 2001). Therefore, researchers set out to determine whether these pupfish subspecies, which have been separated for less than 4000 years, had diverged in AVT signaling to enable differences in territoriality. They found was that pupfish of both sexes from the Amargosa River possessed larger AVT neurons relative to same-sex individuals from Big Spring (Lema and Nevitt 2004b). Further, the researchers functionally determined whether AVT had a role in territoriality by administering AVT to pupfish from both populations; indeed, this treatment caused pupfish to become less aggressive (Lema and Nevitt 2004a).

One of the most striking examples of behavioral plasticity, and a hallmark of eusocial insects, is a division of reproductive behavior (West-Eberhard 1989). In particular, fecund individuals ('queens') exhibit very little care to their offspring while other, less fecund (or often sterile) 'worker' individuals provide sibling care, and the individual development of these alternate forms is largely dictated by environmental conditions. Although eusociality has independently evolved in several insect lineages (bees, wasps, ants, and termites), this extreme developmental plasticity in reproductive behavior is governed by similar physiological mechanisms in all of them (Corona et al. 2016). And although there are important differences in how these mechanisms are regulated among different lineages, in all cases they channel nutritional information into behavioral phenotypes through insulin signaling. Among eusocial lineages, the caste system is a highly evolved developmental system, with a large evolutionary distance from lineages that are not eusocial. This makes comparative studies with ancestral-type populations difficult to conduct. Nonetheless, some research groups have taken creative approaches to shed light on how environmentally sensitive physiological responses have been evolutionarily modified to yield such elaborate societies.

For instance, Chandra and colleagues (2018) studied an ant species, the clonal raider ant Ooceraea biroi, which has secondarily lost queens but in which workers display cooperative brood care, such that reproductive asymmetry still exists within colonies. Thus, while this species is derived with respect to reproductive biology, it is similar to the presumed ancestral subsocial state of ants. These researchers focused on the functional role of insulin-like peptide 2 (ilp2) in promoting environmentally dependent reproductive behavior in the ancestral-type species $O$. biroi. The study found that the removal and addition of larval ants up- and down-regulated ilp2 levels, respectively, and they did so independently of condition, suggesting that social signals per se can mediate insulin signaling. Further, by injecting the $O$. biro $i$ ILP2 peptide into workers, the researchers were able to initiate reproduction in these workers, even in the presence of larvae, which are otherwise an inhibitive cue. The findings of this study suggest a plausible scenario in which, during the transition 
from solitary to subsocial life, insulin signaling - which is canonically sensitive to nutrition - in adults became responsive to larval signals. Adults with low nutritional stores and ILP2 levels may have been more sensitive to larval signals, suppressing their own reproduction and initiating sibling care. Conversely, adults with high nutritional stores and ILP2 levels would have been less sensitive to larval signals and more likely to reproduce, despite the presence of larvae. In eusocial lineages, a similar type of asymmetry could have been modified by natural selection to ultimately produce sterile workers and obligately reproductive queens.

Another approach to understanding the environmentally sensitive origins of eusociality has been to utilize a species of bee that is facultatively social. For example, the sweat bee Megalopta genalis expresses both solitary and social strategies within the same populations, and this facultative expression of sociality is induced by the social and nutritional environment. Specifically, nest-founding females actively adjust the quality and quantity of resources provided to their daughters, which generates physiological differences - again through insulin signaling - that, in turn, govern reproductive behavior (Kapheim et al. 2012; Kapheim 2017). Further, researchers have found that genes involved with the facultative expression of sociality in sweat bees were derived from a set of genes anciently involved in development, supporting the hypothesis that developmental plasticity is intrinsic to the evolution of eusociality (Kapheim et al. 2020). More generally, eusocial insects possess a variety of attributes that make them a promising group in which to determine how environmentally dependent physiological mechanisms contribute to behavioral diversification (Jones and Robinson 2018).

\subsection{PHYSIOLOGICAL MECHANISMS, PLEIOTROPY, AND EVOLUTION}

Physiological mechanisms are intrinsically pleiotropic in nature: hormones, as an example, typically influence whole suites of traits (Ketterson and Nolan 1999; Nijhout 2003). As a consequence, the phenotypic responses we have described, such as developmental timing and morphology, are not mutually exclusive. For example, selection that has caused divergence in developmental timing among spadefoot toads has gone hand in hand with changes in limb and snout lengths (Gomez-Mestre and Buchholz 2006). Conversely, selection on threshold morphologies in beetles results in a corresponding change in developmental timing because the higher JH levels needed for horn induction also influence molting (Moczek and Nijhout 2002). We begin this section by examining how such physiological pleiotropy influences the evolution of plastic phenotypes; we conclude by exploring how such divergence in physiology can then spur the subsequent evolution of other traits or even reproductive isolation.

\subsubsection{Physiological Pleiotropy as a Constraint}

The pleiotropic nature of physiological systems means that correlated traits can be at odds with each other. This antagonism would happen if an increase in the expression of a beneficial trait is linked to a corresponding decrease in a different favorable trait or, alternatively, to an increase in the expression of a maladaptive trait. For instance, a hormonal mechanism often implicated in tradeoffs between different male traits is 
testosterone, which can augment male reproductive success by helping males secure territories but impedes reproductive success by lowering offspring survival due to its detrimental effects on parental care (Hau 2007). Likewise, increased insulin signaling is thought to increase growth and reproductive output at the cost of a reduced lifespan (Figure 5.2; Dantzer and Swanson 2012).

How might we detect physiological pleiotropy? If selection is acting on variation in the overall levels (i.e., production or release) of a systemic hormone, we might expect that hormone titers vary consistently across species to match their environmental conditions (Vitousek et al. 2019). Further, we would expect that traits influenced by that hormone will respond together. If these traits cannot be easily dissociated from each other, one prediction is that we should see a consortium of traits covarying with hormone titers across species. Such covariance has been studied in a suite of life-history

(a)
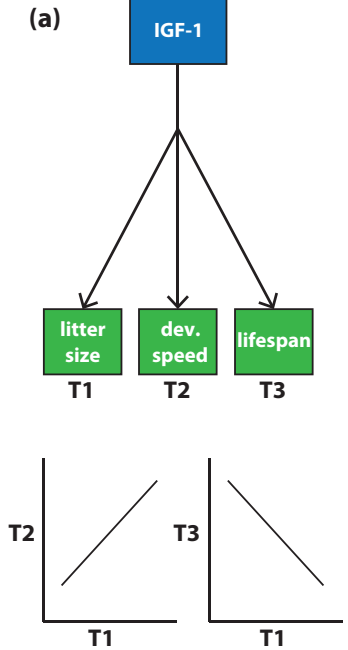

(b)
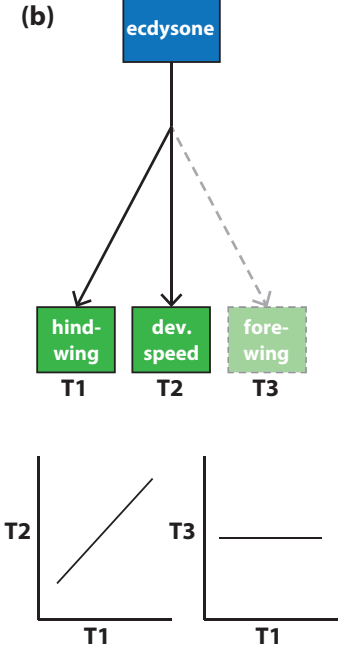

(c)
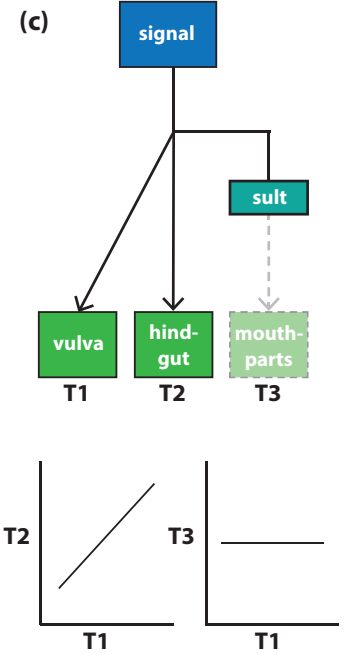

FIGURE 5.2 Breaking physiological pleiotropy. Physiological pleiotropy occurs when a physiological mechanism influences multiple traits and can potentially constrain the evolution of plastic phenotypes. To illustrate, we show systemically acting mechanisms ('signals') in blue, and the hypothetical traits they influence ('T1,' 'T2,' and 'T3') in green. Arrows indicate the influence of a signal on the receiving trait. When traits are linked by a common signal, they will covary as the signal strength changes due to plasticity within species, or selection across species (a). In mammals, for example, if selection favors an increase in IGF-1 because it causes adaptive increases in litter size and developmental speed, it can cause a correlated maladaptive reduction in lifespan. Such pleiotropy can be mitigated via a traitspecific reduction in sensitivity to the signal (b). For instance, ecdysone receptor expression is absent in the forewing spots of Bicyclus anynana, rendering them unresponsive to the same environmentally sensitive levels of ecdysone that govern plasticity in hindwing spots. Additionally, pleiotropy can be alleviated by introducing an intermediate modifier (depicted in teal) that dials signal intensity in a trait-specific fashion (c). In polyphenic nematodes (Pristionchus pacificus), the receptors NHR-40 and NHR-1, which regulate the expression of alternate mouthparts, are expressed elsewhere in the organism; an intermediate enzyme (sulfotransferase, 'sult') specific to mouthpart-producing cells locally mediates the influence of a hypothetical signal without disrupting other traits. 
traits that are influenced by the hormone insulin-like growth factor-1 (IGF-1) (Swanson and Dantzer 2014). This study found that, across mammals, higher levels of IGF-1 were associated with fast life histories, suggesting that the evolution of IGF-1 titers can occur more rapidly than the sensitivities of tissues to it. One interpretation of these studies is that physiological mediators evolve to match environmental conditions, but trait correlations are conserved, potentially limiting adaptive evolution.

\subsubsection{Physiological Pleiotropy as an Integrator}

An alternative interpretation of the IGF-1 survey in mammals is that the suite of traits linked to this hormone, which operate well together, can be rapidly changed in response to changing selective pressures via tweaks to their common physiological mechanism, thus spurring rapid multivariate adaptation (Ketterson et al. 2009). Genetically correlated traits can synergistically accelerate evolution when selection favors a simultaneous increase or decrease in both (Lande and Arnold 1983; Falconer and Mackay 1996; Agrawal and Stinchcombe 2009). In the same way, a physiological mechanism that influences a suite of traits all performing a common function can promote the evolution of a coordinated response to environmental change (AdkinsRegan 2008; McGlothlin and Ketterson 2008).

That suites of correlated and favorable traits might arise suddenly through a physiological modification and promote adaptation may seem unlikely. However, if past selection pressures have already produced an adaptive and integrated suite of traits, they may still work well together even when they are placed in a new context, whether through plasticity or an evolutionary shift. At one extreme end of this scenario, physiologically mediated suites of traits can be transplanted between life stages or sexes (Raff and Wray 1989; West-Eberhard 2003). For example, sibling care in eusocial systems (described above in Section 5.3.3) may have evolved from the precocious display of maternal care in worker females - which have not yet initiated reproduction - towards siblings instead of their own offspring (West-Eberhard 1987; Linksvayer and Wade 2005). Indeed, a suite of common genes have been implicated in both sibling and maternal care behavior in Polistes wasps and carpenter bees (Toth et al. 2007; Rehan et al. 2014). These changes in reproductive behavior have come, not by themselves, but hand in hand with a suite of traits such as sensory perception and foraging (West-Eberhard 1987). Likewise, selection for increased aggression in female hyenas now causes their embryos to be bathed in high levels of testosterone, which promotes a suite of male traits that are now also adaptive (Licht et al. 1998). A rapid, multivariate response to selection may thus be achieved through changes in the strength of a physiological mediator (e.g., a hormone concentration) or by changing the context in which a physiological mediator is deployed.

\subsubsection{Breaking Physiological Pleiotropy}

Trait correlations are not a necessary upshot of physiological systems. Alternatively, evolutionary adjustments can occur when the responsiveness of traits to a common physiological mediator is easily broken. In this case, the evolution of otherwise linked traits can proceed independently, eschewing maladaptive side effects for the 
organism. The ways in which responsiveness can be 'broken' are many, from the way a signal is secreted, broken down, transported, metabolized, or sensed (Nijhout 2003). For instance, hormones are sensed by receptors that can have tissue- and life stage-dependent expression, and without the presence of such receptors a hormone signal will not be seen. Thus, variation in receptor expression among traits can alleviate pleiotropy imposed by a system hormone (Figure 5.2).

Let us return to the butterfly Bicyclus anynana, which has highly plastic, ventral hindwing eyespots. As mentioned, ventral hindwing spots in this species differ between two seasonal morphs due to different levels of environmentally dependent ecdysone experienced during their wandering stage. In contrast, ventral forewing spots lack plasticity, even though they are exposed to the same seasonally dependent levels of ecdysone as ventral hindwing spots. These differences in plasticity between forewing and hindwing spots are enabled by differential expression of ecdysone receptor (EcR) in eyespot centers: at the critical stage of development, EcR is present in the central cells of the hindwing spots of both seasonal forms but is absent in the central cells of the forewing spots (Monteiro et al. 2015). Further, whether this plasticity in eyespots is continuous or discrete, and in what direction it responds to temperature, varies among closely related species (van Bergen et al. 2017), indicating that the evolution of eyespot expression is not physiologically constrained.

Additionally, signaling mechanisms may be modified without requiring changes to signals or receivers, but instead through intermediate modulators. As we have seen in the nematode Pristionchus pacificus, mouthpart plasticity is controlled by two receptors, NHR-40 and NHR-1, which directly instruct developmental outputs (Kieninger et al. 2016; Sieriebriennikov et al. 2020). Both receptors are expressed throughout the body of the nematodes and are thus likely regulate several organismal processes besides mouth polyphenism. Furthermore, the DNA-binding activity of at least NHR-40 is highly conserved with other species, ruling out that feature of the receptor as a likely target for selection on plastic phenotypes (Bui and Ragsdale 2019). However, additional enzymes, which have more localized expression and no observed pleiotropy, completely toggle the influence of NHR-40 and NHR-1 (Ragsdale et al. 2013; Bui et al. 2018; Namdeo et al. 2018; Sieriebriennikov et al. 2018). Further, the genes encoding two of these enzymes vary dramatically in their copy number across nematode lineages with the polyphenism (Biddle and Ragsdale 2020). Therefore, it is possible to amplify the effects of tissue-specific signaling modifiers through dosage, whether in copy number or expression level. In this case, selection could act on specific traits without disturbing conserved, system-wide processes.

\subsubsection{Variability in Physiological Pleiotropy as Substrate for Evolution}

Now that we have addressed both maladaptive pleiotropy that constrains evolution and beneficial pleiotropy that promotes evolution, we will consider what happens when pleiotropy is variable. The effects that physiological responses can have on correlated traits can vary by genetic background, and therefore pleiotropy itself can evolve. Genetic variation in pleiotropy is particularly interesting when considering populations experiencing a novel environmental context. Such a context might cause a hormone to be expressed at a higher maximum, for a longer duration, during a 
different life stage, or even in a different sex than it typically is. Because the physiological response has not yet been tested in this new context, selection has not had the opportunity to filter variation in pleiotropic relationships with that physiological response. Thus, when populations encounter novel conditions, they may unleash a reservoir of variation - which previously existed as 'cryptic genetic variation' - via phenotypic plasticity, including variation that is neutral, adaptive, and maladaptive (Ledón-Rettig et al. 2014; Paaby and Rockman 2014) (Figure 5.3). In cases where at least some of the variation is adaptive, this variation can promote trait evolution.

The expression of cryptic genetic variation is often viewed through the lens of buffering mechanisms, which are themselves physiological systems. The classic experiments of Waddington (Waddington 1953; see also Pfennig 2021 this volume), which implied a mechanism buffering standing genetic variation from its expression, would later be realized by more mechanistic studies (Rutherford and Lindquist 1998; Queitsch et al. 2002). When these buffering mechanisms fail due to environmental or genetic stress, the underlying causal genetic variation - in quantitative genetics terms, 'liability' (Falconer and Mackay 1996; Gibson and Dworkin 2004) - becomes phenotypically expressed. Physiological factors such as hormones, which are environmentally sensitive and systemic, are a perfect candidate link between an environmental stimulus and the expression of such underlying genetic variation. For instance, Suzuki and Nijhout (2006) found that, in a population of tobacco hornworm (Manduca sexta), mechanisms controlling the regulation of the developmental hormone $\mathrm{JH}$ had likely acted as a capacitor for genetic variation in coloration until those mechanisms were disrupted - by genetic and environmental stress - at which point standing genetic variation in the regulation of and sensitivity to $\mathrm{JH}$ was revealed in the population.
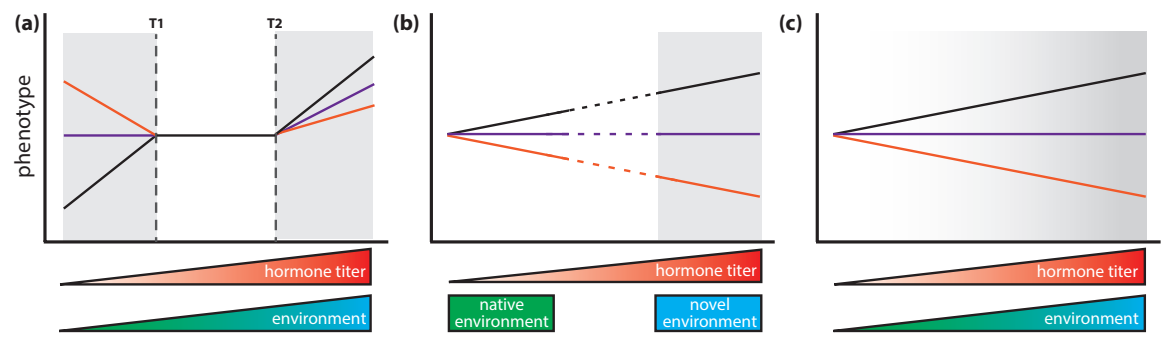

FIGURE 5.3 Physiological mediators as they relate to the expression of cryptic genetic variation. Under native environmental conditions, the effects of a physiological mediator, such as a hormone titer, have uniform or nearly uniform effects on phenotypes across genotypes in a population. If a population experiences extreme environmental conditions (depicted in gray), hormonal titers might be pushed beyond their buffering thresholds (T1 and T2), and variable relationships between genotypes (black, purple, and orange), the hormone, and the resulting phenotypes might be revealed (a). Cryptic genetic variation might also be uncovered when a population experiences a novel and discrete environment, even if the underlying reaction norms are continuous (b). Although it is easiest to model the evolutionary consequences of cryptic genetic variation under the assumption of discrete environments (panels a and b), conditionally expressed genetic variation may, in principle, also be continuous (c). However, the implications of this more biologically realistic variation await better description, both theoretically and empirically. 
To explain this scenario in a natural population, we return to spadefoot toads, but this time with respect to a novel larval feeding strategy: predaceous carnivory. In the Spea clade, tadpoles have the ability to develop as ancestral-type omnivore morphs, which are passive and feed on decaying plant and animal material; alternatively, they develop as carnivorous and often cannibalistic morphs that are aggressive and specialize on shrimp and tadpole prey (Pfennig 1990; Ledón-Rettig and Pfennig 2011). Experiments have shown that feeding a closely related ancestral-type species the novel diet (shrimp) exposes genetic variation in traits associated with the novel larval feeding strategy (Ledón-Rettig et al. 2010a; Levis et al. 2018). Additionally, consuming the novel diet increases their levels of endogenous CORT in this ancestral-type species (Ledón-Rettig et al. 2010b), and treating them with exogenous CORT while feeding them their native diet recapitulates the increases in genetic variance (LedónRettig et al. 2010a). Taken together, these findings implicate diet-induced changes in CORT as a mechanism mediating the expression of previously cryptic genetic variation, specifically variation that could be selected to allow the evolution of a novel feeding strategy.

\subsubsection{How Does Physiological Divergence Promote Diversification?}

In this section, we have so far addressed the question of how free or constrained physiological responses are to evolve. A different question is how the evolution of physiological mechanisms promotes subsequent evolution. Here we highlight two processes that can result from physiological divergence - range expansion and differences in reproductive timing - using a North American songbird, the darkeyed junco.

The evolution of physiological mechanisms can help populations expand into new habitats where they were not previously able to exist, allowing new or relaxed selection pressures to act on traits (Price et al. 2003; Ghalambor et al. 2007). Although dark-eyed juncos (Junco hyemalis) inhabit most of North America, they have also colonized a novel, urban habitat within San Diego, California (ca. 1983). This new yet stable population experiences an environment dramatically different from the montane environment: increased noise and light levels, constant human disturbances, and novel predators, all of which are ways that would likely favor a bolder, more fearless personality (Sloan Wilson et al. 1994; Sih et al. 2004). A candidate mechanism that might govern variation in such personality traits is the stress axis: more robust stress responses (e.g., higher levels of CORT) are associated with shy personalities while muted stress responses are associated with bolder, fearless personalities (Koolhaas et al. 1999). Indeed, researchers found that juncos from the San Diego population exhibit bolder exploratory behavior than a nearby $(70 \mathrm{~km})$ montane population and, likewise, lower maximum CORT levels (Atwell et al. 2012). Importantly, by detecting persistent differences between the two populations under common garden conditions, they found compelling evidence that the variation in both physiology and associated behaviors is due to genetic divergence, and that rapid evolution of CORT responses and boldness can occur.

Interestingly, the contemporary evolution of physiological mechanisms in juncos that allowed them to expand into a novel environment also indirectly promoted 
genetic evolution in other traits. The change in habitat (a milder climate and more abundant food) resulted in colonists experiencing a much longer breeding season. This extended breeding period effectively reduces the social challenges imposed by an annual competition for mates, and males correspondingly produce less testosterone (Atwell et al. 2014). However, while the differences in testosterone between urban and mountain juncos are entirely plastic, differences in plumage patterns - which are typically mediated by testosterone - have genetically diverged between the two populations. In other words, once urban juncos produced atypically low titers of testosterone in response to their novel environment, selection on (or drift in) genetic variation in the sensitivity of plumage to this hormone caused them to diverge genetically from montane populations. Thus, a muted HPA response may have allowed juncos to expand into a new habitat, and novel or relaxed selective pressures introduced by that habitat thereafter resulted in an evolutionary divergence of an unrelated trait.

In addition to geographic isolation, the divergence of physiological mechanisms underlying plasticity in the reproductive timing of conspecific individuals can lead to reproductive isolation (Taylor and Friesen 2017). These differences in reproductive timing (also called 'allochrony') can occur even within a population inhabiting the same geographic area. Although the importance of sympatric speciation is debated, there are compelling examples where such divergence at a physiological level is taking place. For example, two subspecies of juncos seasonally coexist in the Eastern United States during their non-breeding season, foraging together in mixed flocks (Cristol et al. 2003). However, their underlying physiologies begin to change as the breeding season approaches (Fudickar et al. 2016). Even when kept under common garden conditions that mimic changes in photoperiod that occur in late winter, sedentary dark-eyed juncos (J. h. carolinensis) produce higher levels of testosterone and larger testes to prepare them for breeding, while migratory juncos (J. h. hyemalis) possess larger fat stores to help them prepare for migration (Fudickar et al. 2016). The physiological differences between the subspecies' response to photoperiod likely inhibit gene flow between migrants and residents, thus creating the potential for reproductive isolation.

\subsection{CONCLUSIONS}

In this chapter, we have highlighted examples where environmentally sensitive physiological responses generate variation within populations and may have even spurred trait diversification among lineages. Given that variation in physiology can be selected upon to produce evolutionary change in laboratory experiments (Suzuki and Nijhout 2006) and that the same process is often invoked in adaptive radiations (Pfennig et al. 2010; Susoy et al. 2015), a major goal now is to connect our laboratory observations with the rich diversity we see in nature (see Box 5.1). Towards this goal, as seen in our examples, physiological divergence is being studied in populations undergoing dramatic environmental change - and commensurate changes in selective regimes - due to the hand of human intervention, whether that be climate change (see Diamond and Martin 2021 in this volume), transportation, urbanization, or even restoration efforts. Under these accelerated conditions, it may be possible to characterize the processes that occur over longer evolutionary timescales. 
Because evolutionary diversification through plasticity-led evolution is still a controversial topic (Laland et al. 2014; see also Futuyma 2021; Levis and Pfennig 2021; and Schlichting 2021 in this volume), we propose that a better view into the physiological mechanisms governing plasticity, both within and across lineages, will offer a more nuanced understanding of the potential and the limits of this process. In Box 5.1, we offer some suggestions for future research.

\section{ACKNOWLEDGMENTS}

We thank two anonymous reviewers for their comments on the manuscript. We also acknowledge support from the National Science Foundation (grants DEB-1754136 to C.C.L.-R. and IOS-1911688 to E.J.R.).

\section{BOX 5.1 SUGGESTIONS FOR FUTURE RESEARCH}

- What are the molecular mechanisms underpinning physiological plasticity and how do they evolve? Understanding where heritable variation in physiological responses underlying plasticity resides in a developmental pathway can tell us:

- How pleiotropic a physiological response is likely to be: is it high in the chain of regulatory logic and likely to influence many other traits, or is it terminal and likely dissociable from its ancestral pathway?

- Whether there is bias in how physiological plasticity evolves: does plasticity preferably evolve at a certain node in a physiological pathway? There are at least two ways to approach this question. First, given a clade of organisms that vary in their physiological responses and corresponding plastic phenotypes, one could comparatively quantify, at a molecular level, how the components of a physiological pathway have been modified to produce diversity (e.g., via gene amplification, the addition or subtraction of modifier loci, protein evolution, or novel genes). Second, given a tractable laboratory system, one could use artificial selection to determine whether the evolution of plasticity occurs repeatedly by the same or different modifications.

- Does physiological pleiotropy generally constrain or facilitate the evolution of plastic phenotypes? It can be difficult to delineate when a common physiological mechanism covaries with traits because it is constraining phenotypes or because it has helped promote the diversification those phenotypes. One approach suggests measuring the fitness of individuals alongside physiological parameters and their correlated traits over time (Dantzer and Swanson 2017). This would require extensive effort in many systems but would potentially reveal the evolutionary consequences of physiological pleiotropy. 
- How do physiological responses that affect multiple life stages evolve? The pleiotropy of physiological responses extends not only across traits but also across life stages: when the environment elicits a plastic response in early life, it can persist as a 'carry-over' effect even after individuals have transitioned to a new life stage. Even when a physiological response is adaptive early during life, this response may have a different effect on fitness later during life. Yet, there is little empirical evidence to demonstrate whether carry-over effects can evolve to become more or less sensitive to early life conditions. Quantifying how selection pressures jointly act on physiological plasticity during early and late life stages will be difficult given that (1) environmental conditions may fluctuate across generations and (2) populations may be in intermediate stages of evolution such that adaptation may not be complete (Moore and Martin 2019). Nonetheless, understanding the relationships between the mechanisms underlying carry-over effects and their fitness repercussions can reveal how they evolve and diversify.

- How do physiological responses to novel environments interact with standing genetic variation? Understanding where the raw phenotypic variation for phenotypic change - and even evolutionary innovations - comes from is an outstanding question. However, there is mounting evidence that, in many cases, this variation is preexisting, heritable, and environmentally sensitive (i.e., is cryptic genetic variation). Understanding the physiological systems gating this reservoir of phenotypic variation in natural populations can yield a mechanistic insight into the origins of novel trait expression, and potentially allow us to predict in which other systems and situations this process might be important.

- In situations where lineages have recently split, demonstrating that the same physiological mechanism mediating intraspecific plasticity is responsible for interspecific trait variation could offer an additional method to test hypotheses of genetic accommodation (West-Eberhard 2003). This may not work for long-separated lineages, as underlying mechanisms for trait expression can diverge over evolutionary time. However, demonstrating a common underlying physiological basis to plasticity between lineages may be particularly useful for instances of contemporary evolution.

\section{REFERENCES}

Adkins-Regan, E. 2008. Do hormonal control systems produce evolutionary inertia? Philos. Trans. R. Soc. B Biol. Sci. 363:1599-1609.

Agrawal, A. F., and J. R. Stinchcombe. 2009. How much do genetic covariances alter the rate of adaptation? Proc. R. Soc. B Biol. Sci. 276:1183-1191. 
Alberch, P., S. J. Gould, G. F. Oster, and D. B. Wake. 1979. Size and shape in ontogeny and phylogeny. Paleobiology 5:296-317.

Aranda, A., and A. Pascual. 2001. Nuclear hormone receptors and gene expression. Physiol. Rev. 81:1269-1304.

Atwell, J. W., G. C. Cardoso, D. J. Whittaker, S. Campbell-Nelson, K. W. Robertson, and E. D. Ketterson. 2012. Boldness behavior and stress physiology in a novel urban environment suggest rapid correlated evolutionary adaptation. Behav. Ecol. 23:960-969.

Atwell, J. W., G. C. Cardoso, D. J. Whittaker, T. D. Price, and E. D. Ketterson. 2014. Hormonal, behavioral, and life-history traits exhibit correlated shifts in relation to population establishment in a novel environment. Am. Nat. 184:E147-E160.

Balthasar, V. 1963. Monographie der Scarabaeidae und Aphodiidae der palaearktischen und orientalischen Region. Tschechoslowakische Akademie der Wissenschaften. doi: $10.1086 / 404776$.

Beaman, J. E., C. R. White, and F. Seebacher. 2016. Evolution of plasticity: Mechanistic link between development and reversible acclimation. Trends Ecol. Evol. 31:237-249.

Biddle, J. F., and E. J. Ragsdale. 2020. Regulators of an ancient polyphenism evolved through episodic protein divergence and parallel gene radiations. Proc. R. Soc. B Biol. Sci. 287: 20192595.

Blaxter, M., P. De Ley, J. R. Garey, L. X. Liu, P. Scheldeman, A. Vierstraete, J. R. Vanfleteren, L. Y. Mackey, M. Dorris, L. M. Frisse, J. T. Vida, and W. K. Thomas. 1998. A molecular evolutionary framework for the phylum Nematoda. Nature 392:71-75.

Bohenek, J. R. 2019. Extended Adolescence: The Ecology and Endocrinology of Facultative Paedomorphosis. University of Mississippi, Oxford, MS.

Bose, N., A. Ogawa, S. H. Von Reuss, J. J. Yim, E. J. Ragsdale, R. J. Sommer, and F. C. Schroeder. 2012. Complex small-molecule architectures regulate phenotypic plasticity in a nematode. Angew. Chemie 51:12438-12443.

Brakefield, P. M., F. Kesbeke, and P. B. Koch. 1998. The regulation of phenotypic plasticity of eyespots in the butterfly Bicyclus anynana. Am. Nat. 152:853-860.

Brakefield, P. M., and N. Reitsma. 1991. Phenotypic plasticity, seasonal climate and the population biology of Bicyclus butterflies (Satyridae) in Malawi. Ecol. Entomol. 16:291-303.

Buchholz, D. R., S.-C. V. Hsia, L. Fu, and Y.-B. Shi. 2003. A dominant-negative thyroid hormone receptor blockcorepressors at target genes. Mol. Cell. Biol. 23:6750-6758.

Bui, L. T., N. A. Ivers, and E. J. Ragsdale. 2018. A sulfotransferase dosage-dependently regualtes mouthpart dimorphism in the nematode Pristionchus pacificus. Nat. Commun. 9:4119.

Bui, L. T., and E. J. Ragsdale. 2019. Multiple plasticity regulators reveal targets specifying an induced predatory form in nematodes. Mol. Biol. Evol. 36:2387-2399.

Casasa, S., J. F. Biddle, G. Koutsovoulos, and E. J. Ragsdale. 2021. Polyphenism of a novel trait integrated rapidly evolving genes into ancestrally plastic networks. Mol. Biol. Evol. 38:331-343.

Castelletto, M. L., H. C. Massey, and J. B. Lok. 2009. Morphogenesis of Strongyloides stercoralis infective larvae requires the DAF-16 ortholog FKTF-1. PLoS Pathog. 5:e1000370.

Chandra, V., I. Fetter-Pruneda, P. R. Oxley, A. L. Ritger, S. K. McKenzie, R. Libbrecht, and D. J. C. Kronauer. 2018. Social regulation of insulin signaling and the evolution of eusociality in ants. Science 361:398-402.

Corona, M., R. Libbrecht, and D. E. Wheeler. 2016. Molecular mechanisms of phenotypic plasticity in social insects. Curr. Opin. Insect Sci. 13:55-60.

Crespi, E. J., and R. J. Denver. 2005. Ancient origins of human developmental plasticity. Am. J. Hum. Biol. 17:44-54.

Cristol, D. A., E. B. Reynolds, J. E. Leclerc, A. H. Donner, C. S. Farabaugh, and C. W. S. Ziegenfus. 2003. Migratory dark-eyed juncos, Junco hyemalis, have better spatial memory and denser hippocampal neurons than nonmigratory conspecifics. Anim. Behav. 66:317-328. 
Dantzer, B., and E. M. Swanson. 2017. Does hormonal pleiotropy shape the evolution of performance and life history traits? Integr. Comp. Biol. 57:372-384.

Dantzer, B., and E. M. Swanson. 2012. Mediation of vertebrate life histories via insulin-like growth factor-1. Biol. Rev. 87:414-429.

Denver, R. J. 1997. Environmental stress as a developmental cue: corticotropin-releasing hormone is a proximate mediator of adaptive phenotypic plasticity in amphibian metamorphosis. Horm. Behav. 31:169-179.

Diamond, S. E. and R. A. Martin. 2021. Buying time: Plasticity and population persistence. In D. W. Pfennig, ed., Phenotypic Plasticity and Evolution: Causes, Consequences, Controversies. CRC Press, Boca Raton, FL.

Duellman, W. E., and L. Trueb. 1986. Biology of Amphibians. McGraw-Hill, New York.

Dufty, A. M., J. Clobert, and A. P. Møller. 2002. Hormones, developmental plasticity and adaptation. Trends Ecol. Evol. 17:190-196.

Dulovic, A., and A. Streit. 2019. RNAi-mediated knockdown of daf-12 in the model parasitic nematode Strongyloides ratti. PLoS Pathog. 15:e1007705.

Emlen, D. J., and H. F. Nijhout. 1999. Hormonal control of male horn length dimorphism in the dung beetle Onthophagus taurus (Coleoptera: Scarabaeidae). J. Insect Physiol. 45:45-53.

Falcke, J. M., N. Bose, A. B. Artyukhin, C. Rödelsperger, G. V. Markov, J. J. Yim, D. Grimm, M. H. Claassen, O. Panda, J. A. Baccile, Y. K. Zhang, H. H. Le, D. Jolic, F. C. Schroeder, and R. J. Sommer. 2018. Linking genomic and metabolomic natural variation uncovers nematode pheromone biosynthesis. Cell Chem. Biol. 25:787-796.

Falconer, D. S., and T. F. C. Mackay. 1996. Introduction to Quantitative Genetics. 4th ed. Prentice-Hall, Essex.

Fudickar, A. M., T. J. Greives, J. W. Atwell, C. A. Stricker, and E. D. Ketterson. 2016. Reproductive allochrony in seasonally sympatric populations maintained by differential response to photoperiod: Implications for population divergence and response to climate change. Am. Nat. 187:436-446.

Fürst von Lieven, A., and W. Sudhaus. 2000. Comparative and functional morphology of the buccal cavity of Diplogastrina (Nematoda) and a first outline of the phylogeny of this taxon. J. Zool. Syst. Evol. Res. 38:37-63.

Futuyma, D. J. 2021. How does phenotypic plasticity fit into evolutionary theory? In D. W. Pfennig, ed., Phenotypic Plasticity and Evolution: Causes, Consequences, Controversies. CRC Press, Boca Raton, FL.

Ghalambor, C. K., J. K. McKay, S. P. Carroll, and D. N. Reznick. 2007. Adaptive versus nonadaptive phenotypic plasticity and the potential for contemporary adaptation in new environments. Funct. Ecol. 21:394-407.

Gibson, G., and I. Dworkin. 2004. Uncovering cryptic genetic variation. Nat. Rev. Genet. 5:681-690.

Gilroy, S., and A. Trewavas. 2001. Signal processing and transduction in plant cells: the end of the beginning? Nat. Rev. Mol. Cell Biol. 2:307-314.

Goldstein, I. and I. M. Ehrenreich. 2021. Genetic variation in phenotypic plasticity. In D. W. Pfennig, ed., Phenotypic Plasticity and Evolution: Causes, Consequences, Controversies. CRC Press, Boca Raton, FL.

Gomez-Mestre, I., and D. R. Buchholz. 2006. Developmental plasticity mirrors differences among taxa in spadefoot toads linking plasticity and diversity. Proc. Natl. Acad. Sci. USA. 103:19021-19026.

Goodson, J. L., and A. H. Bass. 2001. Social behavior functions and related anatomical characteristics of vasotocin/vasopressin systems in vertebrates. Brain Res. Rev. 35:246-265.

Gould, S. J. 1977. Ontogeny and Phylogeny. Harvard Universty Press, Cambridge.

Green, J. W. M., L. B. Snoek, J. E. Kammenga, and S. C. Harvey. 2013. Genetic mapping of variation in dauer larvae development in growing populations of Caenorhabditis elegans. Heredity 111:306-313. 
Hardie, J. 1980. Juvenile hormone mimics the photoperiodic apterization of the alate gynopara of aphid, Aphis fabae. Nature 286:602-604.

Hau, M. 2007. Regulation of male traits by testosterone: Implications for the evolution of vertebrate life histories. BioEssays 29:133-144.

Herman, J. J., and S. E. Sultan. 2011. Adaptive transgenerational plasticity in plants: Case studies, mechanisms, and implications for natural populations. Front. Plant Sci. 2:102.

Herrmann, M., W. E. Mayer, and R. J. Sommer. 2006. Nematodes of the genus Pristionchus are closely associated with scarab beetles and the Colorado potato beetle in Western Europe. Zoology 109:96-108.

Holloway, G. J., and P. M. Brakefleld. 1995. Artificial selection of reaction norms of wing pattern elements in Bicyclus anynana. Heredity 74:91-99.

Hotez, P., J. Hawdon, and G. A. Schad. 1993. Hookworm larval infectivity, arrest and amphiparatenesis: The Caenorhabditis elegans daf-c paradigm. Parasitol. Today 9:23-26.

Hu, P. J. 2007. Dauer. In The C. elegans Community, ed., WormBook. WormBook. doi: 10.1895/wormbook.1.144.1.

Johnson, C. K., and S. R. Voss. 2013. Salamander paedomorphosis: Linking thyroid hormone to life history and life cycle evolution. Curr. Top. Dev. Biol. 103:229-258.

Jones, B. M., and G. E. Robinson. 2018. Genetic accommodation and the role of ancestral plasticity in the evolution of insect eusociality. J. Exp. Biol. 221:jeb153163.

Kapheim, K., B. Jones, H. Pan, C. Li, B. Harpur, C. Kent, A. Zayed, P. Ioannidis, R. Waterhouse, C. Kingwell, E. Stolle, A. Avalos, G. Zhang, W. McMillan, and W. Wcislo. 2020. Developmental plasticity shapes social traits and selection in a facultatively eusocial bee. Proc. Natl. Acad. Sci. 117: 13615-13625.

Kapheim, K. M. 2017. Nutritional, endocrine, and social influences on reproductive physiology at the origins of social behavior. Curr. Opin. Insect Sci. 33:62-70.

Kapheim, K. M., A. R. Smith, K. E. Ihle, G. V. Amdam, P. Nonacs, and W. T. Wcislo. 2012. Physiological variation as a mechanism for developmental caste-biasing in a facultatively eusocial sweat bee. Proc. R. Soc. B Biol. Sci. 279:1437-1446.

Ketterson, E. D., J. W. Atwell, and J. W. McGlothlin. 2009. Phenotypic integration and independence: Hormones, performance, and response to environmental change. Integr. Comp. Biol. 49:365-379.

Ketterson, E. D., and V. Nolan Jr. 1999. Adaptation, exaptation, and constraint: A hormonal perspective. Am. Nat. 154:S4-S25.

Kieninger, M. R., N. A. Ivers, C. Rödelsperger, G. V. Markov, R. J. Sommer, and E. J. Ragsdale. 2016. The nuclear hormone receptor NHR-40 acts downstream of the sulfatase EUD-1 as part of a developmental plasticity switch in Pristionchus. Curr. Biol. 26:2174-2179.

Kiontke, K., and W. Sudhaus. 2006. Ecology of Caenorhabditis species. In The C. elegans Community, ed., WormBook. doi:10.1895/wormbook.1.37.1.

Koch, P. B., P. M. Brakefield, and F. Kesbeke. 1996. Ecdysteroids control eyespot size and wing color pattern in the polyphenic butterfly Bicyclus anynana (Lepidoptera: Satyridae). J. Insect Physiol. 42:223-230.

Koolhaas, J. M., S. M. Korte, S. F. De Boer, B. J. Van Der Vegt, C. G. Van Reenen, H. Hopster, I. C. De Jong, M. A. W. Ruis, and H. J. Blokhuis. 1999. Coping styles in animals: current status in behavior and stress-physiology. Neurosci. Biobehav. Rev. 23:925-935.

Kulkarni, S. S., R. J. Denver, I. Gomez-Mestre, and D. R. Buchholz. 2017. Genetic accommodation via modified endocrine signalling explains phenotypic divergence among spadefoot toad species. Nat. Commun. 8:993.

Laland, K., T. Uller, M. Feldman, K. Sterelny, G. B. Müller, A. Moczek, E. Jablonka, J. Odling-Smee, G. A. Wray, H. E. Hoekstra, D. J. Futuyma, R. E. Lenski, T. F. C. Mackay, D. Schluter, and J. E. Strassmann. 2014. Does evolutionary theory need a rethink? Nature 514:161-164.

Lande, R., and S. J. Arnold. 1983. The measurement of selection on correlated characters. Evolution 37:1210-1226. 
Ledón-Rettig, C. C., A. P. Moczek, and E. J. Ragsdale. 2018. Diplogastrellus nematodes are sexually transmitted mutualists that alter the bacterial and fungal communities of their beetle host. Proc. Natl. Acad. Sci. U.S.A. 115:10696-10701.

Ledón-Rettig, C. C., and D. W. Pfennig. 2011. Emerging model systems in eco-evo-devo: The environmentally responsive spadefoot toad. Evol. Dev. 13:391-400.

Ledón-Rettig, C. C., D. W. Pfennig, A. J. Chunco, and I. Dworkin. 2014. Cryptic genetic variation in natural populations: a predictive framework. Integr. Comp. Biol. 54:783-793.

Ledón-Rettig, C. C., D. W. Pfennig, and E. J. Crespi. 2010a. Diet and hormonal manipulation reveal cryptic genetic variation: Implications for the evolution of novel feeding strategies. Proc. R. Soc. B Biol. Sci. 277:3569-3578.

Ledón-Rettig, C. C., D. W. Pfennig, and E. J. Crespi. 2010b. Stress hormones and the fitness consequences associated with the transition to a novel diet in larval amphibians. J. Exp. Biol. 213:2547-2547.

Lema, S. C. 2020. Hormones, developmental plasticity, and adaptive evolution: Endocrine flexibility as a catalyst for 'plasticity-first' phenotypic divergence. Mol. Cell. Endocrinol. 502: 110678.

Lema, S. C. 2014. Hormones and phenotypic plasticity in an ecological context: linking physiological mechanisms to evolutionary processes. Integr. Comp. Biol. 54:850-863.

Lema, S. C., and G. A. Nevitt. 2006. Testing an ecophysiological mechanism of morphological plasticity in pupfish and its relevance to conservation efforts for endangered Devil's Hole pupfish. J. Exp. Biol. 209:3499-3509.

Lema, S. C., and G. A. Nevitt. 2004a. Exogenous vasotocin alters aggression during agonistic exchanges in male Amargosa River pupfish (Cyprinodon nevadensis amargosae). Horm. Behav. 46:628-637.

Lema, S. C., and G. A. Nevitt. 2004b. Variation in vasotocin immunoreactivity in the brain of recently isolated populations of a death valley pupfish, Cyprinodon nevadensis. Gen. Comp. Endocrinol. 135:300-309.

Levis, N. A., A. Isdaner, and D. W. Pfennig. 2018. Morphological novelty emerges from preexisting phenotypic plasticity. Nat. Ecol. Evol. 2:1289-1297.

Levis, N. A. and D. W. Pfennig. 2021. Innovation and diversification via plasticity-led evolution. In D. W. Pfennig, ed., Phenotypic Plasticity and Evolution: Causes, Consequences, Controversies. CRC Press, Boca Raton, FL.

Licht, P., T. Hayes, P. Tsai, G. Cunha, H. Kim, M. Golbus, S. Hayward, M. C. Martin, R. B. Jaffe, and S. E. Glickman. 1998. Androgens and masculinization of genitalia in the spotted hyaena (Crocuta crocuta). 1. Urogenital morphology and placental androgen production during fetal life. J. Reprod. Fertil. 113:105-116.

Linksvayer, T. A., and M. J. Wade. 2005. The evolutionary origin and elaboration of sociality in the aculeate hymenoptera: maternal effects, sib-social effects, and heterochrony. Q. Rev. Biol. 80(3):317-336.

Matsuda, R. 1982. The evolutionary process in talitrid amphipods and salamanders in changing environments, with a discussion of "genetic assimilation" and some other evolutionary concepts. Can. J. Zool. 60:733-749.

McGlothlin, J. W., and E. D. Ketterson. 2008. Hormone-mediated suites as adaptations and evolutionary constraints. Philos. Trans. R. Soc. B Biol. Sci. 363:1611-1620.

Miller, R. R. 1948. The cyprinodont fishes of the Death Valley system of eastern California and southwestern Nevada. Misc. Publ. Museum Zool. Univ. Michigan 68:1-55.

Moczek, A. P., J. Hunt, D. J. Emlen, and L. W. Simmons. 2002. Threshold evolution in exotic populations of a polyphenic beetle. Evol. Ecol. Res. 4:587-601.

Moczek, A. P., and H. F. Nijhout. 2002. Developmental mechanisms of threshold evolution in a polyphenic beetle. Evol. Dev. 4:252-264. 
Monteiro, A., X. Tong, A. Bear, S. F. Liew, S. Bhardwaj, B. R. Wasik, A. Dinwiddie, C. Bastianelli, W. F. Cheong, M. R. Wenk, H. Cao, and K. L. Prudic. 2015. Differential expression of ecdysone receptor leads to variation in phenotypic plasticity across serial homologs. PLoS Genet. 11:e1005529.

Moore, M. P., and R. A. Martin. 2019. On the evolution of carry-over effects.

Namdeo, S., E. Moreno, C. Rödelsperger, P. Baskaran, H. Witte, and R. J. Sommer. 2018. Two independent sulfation processes regulate mouth-form plasticity in the nematode Pristionchus pacificus. Development 145:dev66272.

Nijhout, H. F. 2003. Development and evolution of adaptive polyphenisms. Evol. Dev. 5:9-18. Nijhout, H. F., and D. E. Wheeler. 1982. Juvenile hormone and the physiological basis of insect polymorphisms. Q. Rev. Biol. 57:109-133.

Ogawa, A., G. Bento, G. Bartelmes, C. Dieterich, and R. J. Sommer. 2011. Pristionchus pacificus daf-16 is essential for dauer formation but dispensable for mouth form dimorphism. Development 138:1281-1284.

Ogawa, A., A. Streit, A. Antebi, and R. J. Sommer. 2009. A conserved endocrine mechanism controls the formation of dauer and infective larvae in nematodes. Curr. Biol. 19:67-71.

Paaby, A. B., and M. V. Rockman. 2014. Cryptic genetic variation: Evolution's hidden substrate. Nat. Rev. Genet. 15:247-258.

Pfennig, D. W. 1990. The adaptive significance of an environmentally-cued developmental switch in an anuran tadpole. Oecologia 85:101-107.

Pfennig, D. W. 2021. Key questions about phenotypic plasticity. In D. W. Pfennig, ed., Phenotypic Plasticity and Evolution: Causes, Consequences, Controversies. CRC Press, Boca Raton, FL.

Pfennig, D. W., M. A. Wund, E. C. Snell-Rood, T. Cruickshank, C. D. Schlichting, and A. P. Moczek. 2010. Phenotypic plasticity's impacts on diversification and speciation. Trends Ecol. Evol. 25:459-467.

Pigliucci, M. 2001. Phenotypic Plasticity: Beyond Nature and Nurture. The John Hopkins University Press, Baltimore.

Price, T. D., A. Qvarnström, and D. E. Irwin. 2003. The role of phenotypic plasticity in driving genetic evolution. Proc. R. Soc. B Biol. Sci. 270:1433-1440.

Queitsch, C., T. A. Sangster, and S. Lindquist. 2002. Hsp90 as a capacitor of phenotypic variation. Nature 417:618-624.

Raff, R. A., and G. A. Wray. 1989. Heterochrony: developmental mechanisms and evolutionary results. J. Evol. Biol. 2:409-434.

Ragsdale, E. J., and N. A. Ivers. 2016. Specialization of a polyphenism switch gene following serial duplications in Pristionchus nematodes. Evolution 70:2155-2166.

Ragsdale, E. J., M. R. Müller, C. Rödelsperger, and R. J. Sommer. 2013. A developmental switch coupled to the evolution of plasticity acts through a sulfatase. Cell 155:922-933.

Rehan, S. M., A. J. Berens, and A. L. Toth. 2014. At the brink of eusociality: Transcriptomic correlates of worker behaviour in a small carpenter bee. BMC Evol. Biol. 14:260.

Rogers, W. P., and R. I. Sommerville. 1963. The infective stage of nematode parasites and its significance in parasitism. Adv. Parasitol. 1:109-77.

Rutherford, S. L., and S. Lindquist. 1998. Hsp90 as a capacitor for morphological evolution. Nature 396:336-342.

Scheiner, S. M. and N. A. Levis. 2021. The loss of phenotypic plasticity via natural selection: Genetic assimilation. In D. W. Pfennig, ed., Phenotypic Plasticity and Evolution: Causes, Consequences, Controversies. CRC Press, Boca Raton, FL.

Schlichting, C. D. 2021. Plasticity and evolutionary theory: Where we are and where we should be going. In D. W. Pfennig, ed., Phenotypic Plasticity and Evolution: Causes, Consequences, Controversies. CRC Press, Boca Raton, FL.

Semlitsch, R. D., and H. M. Wilbur. 1989. Artificial selection for paedomorphosis in the salamander Ambystoma talpoideum. Evolution 43:105-112. 
Serobyan, V., E. J. Ragsdale, and R. J. Sommer. 2014. Adaptive value of a predatory mouthform in a dimorphic nematode. Proc. R. Soc. B Biol. Sci. 281:20141334.

Shang, F., J. Niu, B. Y. Ding, W. Zhang, D. D. Wei, D. Wei, H. B. Jiang, and J. J. Wang. 2020. The miR-9b microRNA mediates dimorphism and development of wing in aphids. Proc. Natl. Acad. Sci. USA 17: 8404-8409.

Sieriebriennikov, B., G. V. Markov, H. Witte, and R. J. Sommer. 2017. The role of DAF21/Hsp90 in mouth-form plasticity in Pristionchus pacificus. Mol. Biol. Evol. 34:1644-1653.

Sieriebriennikov, B., N. Prabh, M. Dardiry, H. Witte, W. Röseler, M. R. Kieninger, C. Rödelsperger, and R. J. Sommer. 2018. A developmental switch generating phenotypic plasticity is part of a conserved multi-gene locus. Cell Rep. 23:2835-2843.

Sieriebriennikov, B., S. Sun, J. W. Lightfoot, H. Witte, E. Moreno, C. Rödelsperger, and R. J. Sommer. 2020. Conserved nuclear hormone receptors controlling a novel plastic trait target fast-evolving genes expressed in a single cell. PLoS Genet. 16:e1008687.

Sih, A., A. Bell, and J. C. Johnson. 2004. Behavioral syndromes: an ecological and evolutionary overview. Trends Ecol. Evol. 19:372-378.

Silva, D. P., B. Vilela, B. A. Buzatto, A. P. Moczek, and J. Hortal. 2016. Contextualized niche shifts upon independent invasions by the dung beetle Onthophagus taurus. Biol. Invasions 18:3137-3148.

Simpson, S. J., G. A. Sword, and N. Lo. 2011. Polyphenism in insects. Curr. Biol. 21:R738-R749.

Sloan Wilson, D., A. B. Clark, K. Coleman, and T. Dearstyne. 1994. Shyness and boldness in humans and other animals. Trends Ecol. Evol. 9:442-446.

Smith, H. M. 1969. The Mexican axolotl: Some misconceptions and problems. Bioscience 19:593-597.

Sultan, S. E. 2000. Phenotypic plasticity for plant development, function and life history. Trends Plant Sci. 5:537-542.

Susoy, V., M. Herrmann, N. Kanzaki, M. Kruger, C. N. Nguyen, C. Rödelsperger, W. Röseler, C. Weiler, R. M. Giblin-Davis, E. J. Ragsdale, and R. J. Sommer. 2016. Large-scale diversification without genetic isolation in nematode symbionts of figs. Sci. Adv. 2:e1501031.

Susoy, V., E. J. Ragsdale, N. Kanzaki, and R. J. Sommer. 2015. Rapid diversification associated with a macroevolutionary pulse of developmental plasticity. Elife 4:e05463.

Suzuki, Y., and H. F. Nijhout. 2006. Evolution of a polyphenism by genetic accommodation. Science 311:650-652.

Swanson, E. M., and B. Dantzer. 2014. Insulin-like growth factor-1 is associated with lifehistory variation across Mammalia. Proc. R. Soc. B Biol. Sci. 281:20132458.

Taylor, R. S., and V. L. Friesen. 2017. The role of allochrony in speciation. Mol. Ecol. 26:3330-3342.

Toth, A. L., K. Varala, T. C. Newman, F. E. Miguez, S. K. Hutchison, D. A. Willoughby, J. F. Simons, M. Egholm, J. H. Hunt, M. E. Hudson, and G. E. Robinson. 2007. Wasp gene expression supports an evolutionary link between maternal behavior and eusociality. Science 318:441-444.

van Bergen, E., D. Osbaldeston, U. Kodandaramaiah, O. Brattström, K. Aduse-Poku, and P. M. Brakefield. 2017. Conserved patterns of integrated developmental plasticity in a group of polyphenic tropical butterflies. BMC Evol. Biol. 17:59.

Vellichirammal, N. N., P. Gupta, T. A. Hall, and J. A. Brisson. 2017. Ecdysone signaling underlies the pea aphid transgenerational wing polyphenism. Proc. Natl. Acad. Sci. 114:1419-1423.

Viney, M. E., M. P. Gardner, and J. A. Jackson. 2003. Variation in Caenorhabditis elegans dauer larva formation. Dev. Growth Differ. 45:389-396. 
Vitousek, M. N., M. A. Johnson, C. J. Downs, E. T. Miller, L. B. Martin, C. D. Francis, J. W. Donald, M. J. Fuxjager, W. Goymann, M. Hau, J. F. Husak, B. K. Kircher, R. Knapp, L. A. Schoenle, and T. D. Williams. 2019. Macroevolutionary patterning in glucocorticoids suggests different selective pressures shape baseline and stress-induced levels. Am. Nat. 193:866-880.

Voss, S. R., D. K. Kump, J. A. Walker, H. B. Shaffer, and G. J. Voss. 2012. Thyroid hormone responsive QTL and the evolution of paedomorphic salamanders. Heredity 109:293-298.

Wada, H. 2008. Glucocorticoids: Mediators of vertebrate ontogenetic transitions. Gen. Comp. Endocrinol. 156:441-453.

Waddington, C. H. 1953. Genetic assimilation of an acquired character. Evolution 7:118-126.

Wales, J. H. 1930. Biometrical studies of some races of cyprinodont fishes, from the Death Valley region, with description of Cyprinodon diabolis, $n$. sp. Copeia 3:61-70.

Wang, Z., X. E. Zhou, D. L. Motola, X. Gao, K. Suino-Powell, A. Conneely, C. Ogata, K. K. Sharma, R. J. Auchus, J. B. Lok, J. M. Hawdon, S. A. Kliewer, H. E. Xu, and D. J. Mangelsdorf. 2009. Identification of the nuclear receptor DAF-12 as a therapeutic target in parasitic nematodes. Proc. Natl. Acad. Sci. U SA 106:9138-9143.

West-Eberhard, M. J. 2003. Developmental Plasticity and Evolution. Oxford University Press, Oxford.

West-Eberhard, M. J. 1989. Phenotypic plasticity and the origins of diversity. Annu. Rev. Ecol. Syst. 20:249-278.

West-Eberhard, M. J. 1987. Flexible strategy and social evolution, pp. 35-51. In I. Y. Brown and J. Kikkawa, eds. Animal Societies: Theories and Facts. Scientific Society Press, Tokyo, Japan.

Wiens, J. J., R. M. Bonett, and P. T. Chippindale. 2005. Ontogeny discombobulates phylogeny: paedomorphosis and higher-level salamander relationships. Syst. Biol. 54:91-110.

Wilcox, J. L., and A. P. Martin. 2006. The devil's in the details: Genetic and phenotypic divergence between artificial and native populations of the endangered pupfish (Cyprinodon diabolis). Anim. Conserv. 9:316-321.

Wilecki, M., J. W. Lightfoot, V. Susoy, and R. J. Sommer. 2015. Predatory feeding behaviour in Pristionchus nematodes is dependent on phenotypic plasticity and induced by serotonin. J. Exp. Biol. 218:1306-1313. 